\title{
Original Contributions
}

\section{THE MENTAL HEALTH CONSEQUENCES OF TERRORISM: IMPLICATIONS FOR EMERGENCY MEDICINE PRACTITIONERS}

\author{
Charles DiMaggio, PhD, MPH, PA-C, ${ }^{*}$ Paula A. Madrid, PsyD, $\dagger$ George T. Loo, MPA, MPH, EMT-B, ${ }^{*}$ \\ and Sandro Galea, MD, DRPH $\ddagger$ \\ *Department of Epidemiology and †The Resiliency Program, National Center for Disaster Preparedness, Columbia University Mailman \\ School of Public Health, New York, New York, and łDepartment of Epidemiology, University of Michigan School of Public Health, Ann \\ Arbor, Michigan \\ Reprint Address: Charles DiMaggio, PHD, Department of Epidemiology, Mailman School of Public Health, 722 West 168 Street, \\ New York, NY 10032
}

Abstract-Emergency physicians are likely to be firstline responders in any local or regional terrorist event. In addition to preparing for the potential physical conditions and injuries that are associated with terrorism, they should be aware of the behavioral and mental health implications as well. It is helpful to be familiar with the characteristics that predict who may be at increased risk for mental illness after such events and how they may be identified in an Emergency Department setting. Although most people in the general population with behavioral conditions stemming from a terrorist event can be expected to recover spontaneously within several months, other individuals are at increased risk of developing more debilitating mental health conditions that have been associated with post-terrorist and disaster environments. Screening tools are available to help emergency practitioners identify them and refer patients for more formal psychiatric evaluation and potential interventions to facilitate and speed the recovery process. (C) 2008 Elsevier Inc.

Keywords-terrorism; mental health; post-traumatic stress

Funded by Centers for Disease Control and Prevention Health Protection Research Initiative grant number 1 K01 CE000494-02.

\section{INTRODUCTION}

Behavioral disturbance is the primary objective of terrorism, and emergency physicians are likely to be firstline responders in any local or regional terrorist event (1). Therefore, it is helpful for Emergency Medicine practitioners to be familiar with the behavioral and mental health implications of terrorism and to be aware of potential clinical approaches to the psychological distress associated with such incidents.

The best available evidence suggests that mass trauma events that are incomprehensible and have obvious human intent, such as terrorist events, are associated with great mental health effects in the population (2). The mental health consequences of terrorism run along a continuum from general unease, fear, and anxiety to more formally defined psychiatric disease states such as panic disorder, acute stress disorder (ASD), anxiety disorders including post-traumatic stress disorder (PTSD), and mood disorders such as major depression.

The consequences of terrorist acts extend beyond those immediately affected. For every individual killed in the terrorist attacks of September 11, 2001, an additional 59 persons (including those suffering physical injury and people who were related to the person killed in the attack) were also affected (3). Effective post- 
Table 1. Comparison of Stress Disorders Associated with Terrorism

\begin{tabular}{|c|c|c|}
\hline Disorder & Definition & Diagnostic signs and symptoms \\
\hline Panic attack (4) & $\begin{array}{l}\text { An intense and sudden feeling of } \\
\text { fear and anxiety }\end{array}$ & $\begin{array}{l}\text { Chest pain, nausea, diaphoresis, tachycardia, tachypnea, } \\
\text { paresthesias, and dizziness. Terror that is almost } \\
\text { paralyzing, shaking, feeling of dread, trembling, choking, } \\
\text { hot flashes, or sudden chills, and fear of impending } \\
\text { insanity or death. The attacks themselves are not harmful } \\
\text { and usually subside within 20-30 min. }\end{array}$ \\
\hline Panic disorder $(4,5)$ & $\begin{array}{l}\text { A pattern of recurrent unexpected } \\
\text { panic attacks. }\end{array}$ & $\begin{array}{l}\text { Presence of recurrent, unexpected panic attacks followed } \\
\text { by at least } 1 \text { month of persistent concern about having } \\
\text { another panic attack, worry about the potential } \\
\text { implications or consequences of the attack, or a } \\
\text { significant behavioral change related to the attacks. Rule } \\
\text { out the direct physiological effects of a substance (e.g., } \\
\text { caffeine intoxication), or a general medical condition (e.g., } \\
\text { hyperthyroidism). }\end{array}$ \\
\hline $\begin{array}{l}\text { Acute stress disorder (ASD) } \\
\qquad(4,7)\end{array}$ & $\begin{array}{l}\text { Severe stress symptoms occurring } \\
\text { within a month after a traumatic } \\
\text { event, characterized by } \\
\text { indicators of dissociation. }\end{array}$ & $\begin{array}{l}\text { Avoidance, re-experiencing the event, and increased arousal } \\
\text { within 2-4 days of experiencing a traumatic event. } \\
\text { Presence of three of the following five symptoms labeled } \\
\text { as indicators of dissociation: numbing, reduced } \\
\text { awareness of surroundings, derealization, } \\
\text { depersonalization, and dissociative amnesia. } \\
\text { Cardiovascular reactivity such as tachycardia or } \\
\text { palpitations, prior history of psychiatric disorder, the } \\
\text { presence of depressive symptomatology, avoidance, } \\
\text { history of prior traumatization, and trait neurotism are } \\
\text { strong predictors of both ASD and post-traumatic stress } \\
\text { disorder (PTSD) diagnoses. }\end{array}$ \\
\hline $\begin{array}{l}\text { Post-traumatic stress disorder } \\
\qquad(4,8,9,11-13)\end{array}$ & $\begin{array}{l}\text { Stress disorder lasting longer than } \\
\text { one month from the time of the } \\
\text { traumatic event. }\end{array}$ & $\begin{array}{l}\text { Requires at least one eligible traumatic event ("gateway } \\
\text { criteria"), a symptom of re-experiencing the trauma } \\
\text { (intrusion), a numbing or blunting of affect (avoidance) and } \\
\text { at least two symptoms of hypervigilance and startling } \\
\text { (arousal), of at least } 1 \text { month duration. }\end{array}$ \\
\hline
\end{tabular}

terrorism interventions require the recognition that behavioral and emotional consequences extending beyond those immediately affected are, in fact, the intent of terrorists.

In this article we discuss the mental health consequences of terrorism, which individuals may be at increased risk for mental illness after such events and how they may be identified in an Emergency Department (ED) setting, approaches to clinical care, and aspects of resilience. To the extent possible, we will draw on the growing body of literature that explicitly addresses the mental health consequences of terrorism. However, much of the peer-reviewed information about massevent-related mental health disturbances comes from the general disaster literature and we rely on this extensive work as well.

\section{MENTAL HEALTH DISORDERS ASSOCIATED WITH TERRORISM}

Anxiety

Unease and a certain degree of anxiety and fear are to be expected after a traumatic event such as a terrorist attack. Although discomfiting, general apprehension and unease after experiencing a terrorist attack are not cause for clinical concern. More significant anxiety symptoms, however, may be associated with the development of specific anxiety disorders. The Diagnostic and Statistical Manual of Mental Disorders, $4^{\text {th }}$ edition (DSM-IV) indexes several anxiety disorders, three of which, panic disorder, acute stress disorder, and post-traumatic stress disorder (PTSD), are often associated with traumatic event exposures and are relevant in the postterrorism context (4) (Table 1). Depression is another clinically important condition that may manifest in the post-terrorism environment.

\section{Panic}

A panic attack is an intense and sudden feeling of fear and anxiety. Its presentation may be a challenge to emergency clinicians because it is associated with such alarming physical signs and symptoms as chest pain, nausea, diaphoresis, tachycardia, tachypnea, paresthesias, and dizziness. Additional symptoms of panic attack are terror that is almost paralyzing, shaking, feeling of dread, trembling, choking, hot flashes or sudden chills, and fear of impending insanity or death. The attacks themselves are 
not harmful and usually subside within 20-30 min. Panic disorder refers to a pattern of recurrent unexpected panic attacks.

Panic disorder can occur across a variety of anxiety and mood disorders (5). Patients with panic disorder may be readily encountered in EDs. In one case series, $32 \%$ of patients presenting to an ED with low to moderate risk for acute coronary syndrome met criteria for panic disorder (6). To diagnose panic disorder, it is essential to assess for the presence of recurrent, unexpected panic attacks followed by at least 1 month of persistent concern about having another panic attack, worry about the potential implications or consequences of the attack, or a significant behavioral change related to the attacks. As with many anxiety disorders, it is important to rule out the direct physiological effects of a substance (e.g., caffeine intoxication), or a systemic medical condition (e.g., hyperthyroidism) (4).

\section{Stress}

Severe stress symptoms occurring within a month after a traumatic event can be a sign of Acute Stress Disorder (ASD). The diagnostic criteria for ASD include symptoms of avoidance, re-experiencing the event, and increased arousal within 2-4 days of experiencing a traumatic event (4). The diagnosis of ASD requires the presence of three of the following five symptoms, labeled as indicators of dissociation: numbing, reduced awareness of surroundings, perceiving the external environment as unreal (derealization), perceiving oneself as unreal (depersonalization), and the separation of thoughts, emotions, sensations or memories from the rest of the psyche (dissociative amnesia). Cardiovascular reactivity such as tachycardia or palpitations, depression, a history of trauma, and a tendency toward emotional vulnerability to stress and psychosomatic concerns (trait neurotism) have been found to be strong predictors of both ASD and post-traumatic stress disorder (PTSD) diagnoses (7).

First described in the 1980s and included in the Diagnostic and Statistical Manual of Mental Disorders, $3^{\text {rd }}$ edition (DSM-III), the diagnosis of PTSD arose largely in response to the experiences of war veterans (8). To qualify for a diagnosis, an individual requires at least one eligible traumatic event ("gateway criteria"), a symptom of re-experiencing the trauma (intrusion), a numbing or blunting of affect (avoidance), and at least two symptoms of exaggerated sensitivity to threats (hypervigilance) and increased arousal or response to such perceived threats (startling). The diagnostic criteria underwent revision in the 1987 DSM-III-R when the requirement of at least 1 month's duration was added, and again in DSM-IV when the individual's perception of the event was added to the criteria (9). Work impairment associated with PTSD is as great as that seen in major depressive disorder, and is associated with increased rates of medical utilization (10).

Post-traumatic stress disorder is perhaps the most prevalent and debilitating consequence of disasters and terrorism incidents (11). The core differences between ASD and PTSD are the time elapsed since the traumatic event and the relative emphasis on dissociative presentations such as the unreality of one's self or one's environment in ASD. Research suggests that individuals whose immediate post-disaster symptoms include dissociation, numbing, or derealization are at increased risk for developing post-traumatic stress disorder (PTSD) $(12,13)$.

The symptoms of PTSD may be especially severe when the stressor is of human design (4). A 2005 study comparing victims of terrorism to motor vehicle crash survivors found that exposure to terrorist attacks is followed by a higher incidence of PTSD and higher levels of PTSD symptoms, anxiety, and depression (14). The authors suggested that the intensity of the early response seems to significantly determine the subsequent occurrence of PTSD. The study concluded, though, that once developed, terrorism-related and post-motor vehicle crash PTSD symptoms resolve in a similar way.

\section{Depression}

Depression is a debilitating condition characterized by feelings of extreme sadness and loss of interest in daily activities. Whereas patients with depression or suicidal ideation soon after a terrorist event are likely to present with exacerbations of pre-existing conditions, people exposed to terrorism who develop PTSD also may be at increased risk of experiencing a depressive episode as a co-morbid condition (15). Indications that a patient may be experiencing a clinically significant depressive episode include feelings of hopelessness, thoughts of death, inability to concentrate, insomnia, and a blunted affect (4). Major depressive disorders carry with them an attendant risk of self-harming behavior.

\section{RISK AND RESILIENCE}

The most important predictor of a mental health disorder after a terrorist event is the severity or intensity of exposure. Studies indicate that survivors of terrorist incidents consistently suffer the highest rates of psychiatric disease (16). Rescuers and first responders are at next highest risk. A meta-analysis of terrorism-related mental health disturbance reported that in the year after a terrorist incident, PTSD prevalence in directly affected 
populations varied between $12 \%$ and $16 \%$ (17). In the immediate post-September 2001 attack period, there were reports of anxiety-related diagnoses in almost 50\% of the population of New York City's Chinatown, which was located in the immediate vicinity of the World Trade Center (18). Nearly half of the Australian firefighters involved in battling a bush fire in 1993 had PTSD at some point in the first 2 years after the incident; $13 \%$ of Oklahoma City firefighters met criteria for PTSD several months after the 1995 terrorist bombing of the Alfred P. Murrah Federal Building (11).

Several additional factors have consistently been shown to be associated with risk of psychological disorder after exposure to traumatic events. In one review, 94\% of studies that examined the effect of gender found that being female was associated with an increased risk of post-disaster mental health diagnoses, with women reported as being twice as likely as men to develop PTSD $(2,19)$. It has been suggested that the greater likelihood of psychological disorder in women after terrorism or mass trauma may be mediated by the stress of caring for others and being obligated to provide more resources than are received in the post-disaster environment (2). The only psychological disorder consistently observed to be more common among men after a traumatic event is alcohol abuse (2).

Although the data are inconsistent, several studies have shown that minority and lower socioeconomic status are associated with increased risk of post-disaster mental health disorders. After the September 11, 2001 terrorist attacks, New York City residents of lower socioeconomic status were two and half times more likely to develop PTSD than those at higher income level, and there were reports of increased alcohol and tobacco use among drug users $(20,21)$. However, these associations are likely to be mediated through increased exposure to the immediate effects of disasters (16).

Loss of psychosocial resources, such as family, friends, and jobs, as well as relocation and disruption of neighborhood patterns are also key mediators of postdisaster behavioral disturbances, and pre-existing psychiatric conditions predispose individuals to post-disaster PTSD (16). The presence of social and familial supports and an individual's desire and ability to use them is a crucial aspect of the recovery process $(22,23)$.

In contrast to factors that predispose persons to mental health disorders after terrorism, recent research has focused on resilience after terrorism and traumatic experiences. Resilience has been defined as the ability to engage in healthy functioning in an unhealthy setting and as the maintenance of mastery under stress (24-26). There is agreement on the existence of a relatively small set of global factors associated with resilience. They include a combination of positive internal resources, family system functioning, and external resources that ensure healthy functioning $(27,28)$.

Findings in the last decade have highlighted how common is the phenomenon of resilience. It is a basic adaptive and protective human mechanism (29). Individuals possess many "internal resources" they can call upon to mediate risk (27). Temperament, cognitive functioning, self-efficacy, shyness, and intelligence are examples of internal resources often cited as related to outcomes $(27,28)$. Enhancement of self-esteem and generalized efficacy, improved communication and conflict mediation skills, and other domains of cognitive problemsolving are related to increased resilience. In many respects, the mechanisms of coping are less important than whether a person accepts and believes that he or she can cope (16).

\section{IDENTIFICATION AND INTERVENTION}

Early encounters with persons who have experienced a terrorist attack may provide an opportunity to identify those who may be at risk for suffering from the adverse consequences of this experience. A brief, focused history aimed at documenting potential risk factors, such as degree of exposure, psychiatric history, or loss of social supports, may help identify patients in need of additional screening (19).

Several relatively brief, validated instruments are available to help identify the mental health conditions most likely to occur in the aftermath of terrorism. A list and short descriptions are presented in Table 2. References are provided for more detailed information on the instruments themselves. Researchers have demonstrated the successful use of these types of instruments in the ED setting (6).

The initial approaches to mitigating the mental health consequences of terrorism involve patient education and support, referral for formal psychiatric evaluation and counseling and, where necessary, pharmacological interventions. Evidence suggests that most individuals experiencing fear and minor physical symptoms in the aftermath of mass events improve spontaneously, and that simply reminding people that most symptoms will resolve may be helpful (30). Although it may be difficult in the busy ED setting, clinicians should devote some time to describing how well most individuals cope under extreme circumstances, and encouraging people to resume their routine activities if possible $(31,32)$.

The presence of social and familial supports and an individual's desire and ability to use them is a crucial aspect of any recovery process $(22,23)$. Early interventions may involve assisting individuals in the development of skills that facilitate their utilization of interper- 
Table 2. Selected Mental Health Screening Instruments for the Emergency Department Setting

\begin{tabular}{|c|c|c|c|c|c|c|}
\hline $\begin{array}{l}\text { Name of } \\
\text { Instrument }\end{array}$ & Target Disorder & Description & Strengths & Weaknesses & Sensitivity/Specificity & Time Required \\
\hline $\begin{array}{l}\text { Mental Health } \\
\text { Inventory } \\
\text { (MHI-5) } \\
(50,51)\end{array}$ & Mood and anxiety & $\begin{array}{l}\text { 5-item short version derived } \\
\text { from the } 38 \text {-item longer } \\
\text { version; two items of the } \\
\text { MHI-5 focus on } \\
\text { symptoms of anxiety and } \\
\text { the remainder on } \\
\text { symptoms of mood } \\
\text { disorders }\end{array}$ & $\begin{array}{l}\text { Self-administered } \\
\text { pen-and-paper form } \\
\text { designed to screen } \\
\text { general clinical } \\
\text { patients for } \\
\text { psychopathology }\end{array}$ & $\begin{array}{l}\text { Does not detect substance } \\
\text { abuse; not suitable for } \\
\text { children or psychiatric } \\
\text { population; lacks power } \\
\text { to detect a broad range } \\
\text { of psych disorders }\end{array}$ & $\begin{array}{l}\text { Mood disorders sensitivity } 0.83 ; \\
\text { specificity } 0.78 \text {; anxiety } \\
\text { disorders sensitivity } 0.73 ; \\
\text { specificity } 0.60 \text {; mood or } \\
\text { anxiety disorders sensitivity } \\
0.69 ; \text { specificity } 0.71 ; \text { any } \\
\text { disorder (substance use } \\
\text { excluded); sensitivity } 0.69 ; \\
\text { specificity } 0.61 \text {. }\end{array}$ & $\begin{array}{l}\text { 5-item version } \\
\text { takes } 5 \text { min }\end{array}$ \\
\hline $\begin{array}{l}\text { General Health } \\
\text { Questionnaire } \\
\text { (GHQ) } \\
(50,52)\end{array}$ & $\begin{array}{l}\text { Daily functioning, } \\
\text { psychological } \\
\text { disorders } \\
\text { related to } \\
\text { general illness, } \\
\text { mood disorders }\end{array}$ & $\begin{array}{l}\text { Self-report instrument with a } \\
\text { 4-point response scale }\end{array}$ & $\begin{array}{l}\text { Self-report pen-and- } \\
\text { paper form that is } \\
\text { suitable for all age } \\
\text { groups; available in } \\
\text { multiple languages }\end{array}$ & $\begin{array}{l}\text { Not to be used to } \\
\text { determine life-long } \\
\text { psychological disorders }\end{array}$ & $\begin{array}{l}\text { Cutoff of } 2.5 \text { results in } \\
\text { sensitivity of } 0.64 \text { and } \\
\text { specificity of } 0.74 \text {. }\end{array}$ & $\begin{array}{l}\text { 12-item } \\
\text { version, } \\
3-15 \text { min to } \\
\text { complete }\end{array}$ \\
\hline $\begin{array}{l}\text { Brief Symptom } \\
\text { Inventory } \\
\text { (BSI) }(50,53)\end{array}$ & $\begin{array}{l}\text { Psychological } \\
\text { distress or } \\
\text { somatic } \\
\text { symptoms }\end{array}$ & $\begin{array}{l}\text { A brief self-report symptom } \\
\text { scale }\end{array}$ & $\begin{array}{l}\text { Comparable in reliability } \\
\text { and validity to the } \\
\text { longer parent scale; } \\
\text { available in multiple } \\
\text { languages }\end{array}$ & $\begin{array}{l}\text { Not suitable for children; } \\
\text { results may be } \\
\text { influenced by other } \\
\text { psychological disorders. }\end{array}$ & $\begin{array}{l}\text { Consistently identified } 84 \% \text { of } \\
\text { cancer patients who were } \\
\text { clinically diagnosed with } \\
\text { distress }\end{array}$ & 8 to $10 \mathrm{~min}$ \\
\hline $\begin{array}{l}\text { Life Experience } \\
\text { Survey (LES) } \\
(50,54)\end{array}$ & Stress disorders & $\begin{array}{l}\text { Designed to assess the } \\
\text { influence of environmental } \\
\text { stressors on stress } \\
\text { disorders }\end{array}$ & $\begin{array}{l}\text { Short and easy to } \\
\text { administer, no } \\
\text { training required }\end{array}$ & $\begin{array}{l}\text { Test-retest susceptible to } \\
\text { changes in life events } \\
\text { over the course of } \\
\text { administrations }\end{array}$ & $\begin{array}{l}\text { 7-point scale ranging from }-3 \\
\text { to } 0 \text { to }+3\end{array}$ & $10 \mathrm{~min}$ \\
\hline $\begin{array}{l}\text { Primary Care } \\
\text { PTSD } \\
\text { Screen } \\
\text { (PC-PTSD) } \\
\text { (55) }\end{array}$ & PTSD & $\begin{array}{l}\text { The PC-PTSD is brief and } \\
\text { problem-focused }\end{array}$ & $\begin{array}{l}\text { Assesses four basic } \\
\text { PTSD symptoms }\end{array}$ & $\begin{array}{l}\text { Does not contain trauma } \\
\text { event-related questions }\end{array}$ & & $\begin{array}{l}4 \text { yes or no } \\
\text { questions }\end{array}$ \\
\hline $\begin{array}{l}\text { PTSD Checklist } \\
\text { Civilian } \\
\text { Version } \\
\text { (PCL-C) } \\
\text { (56-58) }\end{array}$ & PTSD & & $\begin{array}{l}\text { Used when structured } \\
\text { clinical interview not } \\
\text { possible; abbreviated } \\
\text { versions (2-item, } \\
\text { 3-item, 4-item, } \\
\text { 6-item) available }\end{array}$ & & $\begin{array}{l}\text { Cutoff of } 5 \text { on } 3 \text {-item version } \\
\text { results in a sensitivity of } .90 \\
\text { and a specificity of } .60 .\end{array}$ & $\begin{array}{l}\text { 17-item } \\
5 \text {-point } \\
\text { scale takes } \\
5 \text { min }\end{array}$ \\
\hline $\begin{array}{l}\text { Patient Health } \\
\text { Questionnaire } \\
\text { (59) }\end{array}$ & Depression & $\begin{array}{l}\text { Half the length of many } \\
\text { other depression } \\
\text { measures, with } \\
\text { comparable sensitivity } \\
\text { and specificity }\end{array}$ & $\begin{array}{l}\text { Assesses nine } \\
\text { symptoms of } \\
\text { depression; multiple } \\
\text { languages }\end{array}$ & Screening purposes only & $\begin{array}{l}\text { Cutoff of } 9 \text { results in sensitivity } \\
\text { of } 0.95 \text { and specificity of } \\
0.84 \text {. }\end{array}$ & 3 min or less \\
\hline $\begin{array}{l}\text { CAGE } \\
\text { questionnaire } \\
\text { (50) }\end{array}$ & $\begin{array}{l}\text { Alcohol use } \\
\text { problem }\end{array}$ & $\begin{array}{l}\text { Mnemonic screening device: } \\
\text { Cut Down, Annoyed, } \\
\text { Guilty and Eye Opener; } \\
\text { can be administered in } \\
\text { variety of treatment or } \\
\text { non-treatment settings }\end{array}$ & $\begin{array}{l}\text { Brief, multiple } \\
\quad \text { languages available }\end{array}$ & & $\begin{array}{l}\text { Cutoff of } 2 \text { results in a } \\
\text { sensitivity of } 0.78 \text { to } 0.81 \text { and } \\
\text { a specificity of } 0.76 \text { to } 0.96\end{array}$ & $<1 \min$ \\
\hline
\end{tabular}




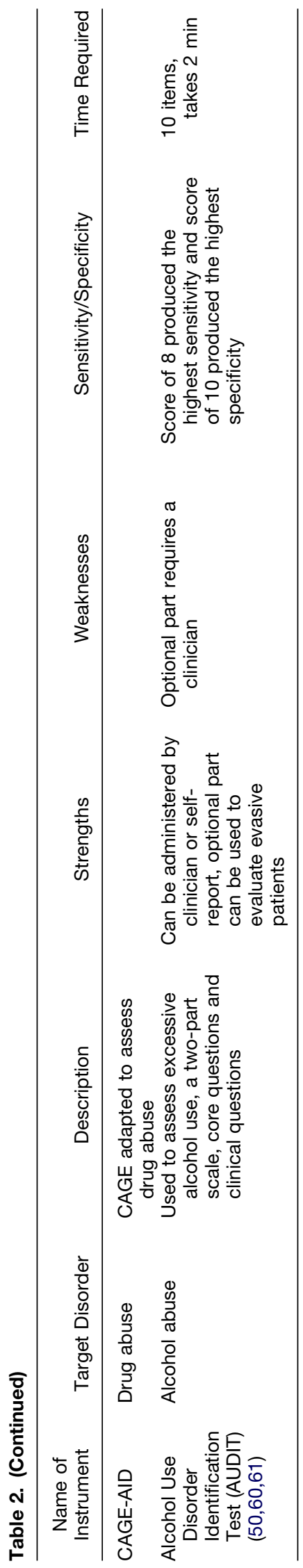

sonal supports and other coping mechanisms (33). This is particularly relevant because the aftermath of trauma often disrupts people's sense of the world as a predictable, safe place (34). It is important to consider that a desire not to discuss the trauma and to avoid reminders of it may be part of coping (35). Initial ED interventions may consist of education in the form of validating and supportive conversations as well as handouts or flyers that describe trauma and its impact, providing information on where to get help and tips on coping and stress management techniques that can be helpful in the postevent environment (36). Although most ED practitioners will not provide more formal mental health interventions such as behavioral therapy and counseling, they should be aware of them so they can make informed decisions about referrals.

There is some controversy over which formalized mental health interventions work best during the initial short-term aftermath of trauma and which are best for particular populations of exposed or directly affected individuals. Although there have been no randomized clinical trials of post-disaster behavioral interventions, critical incident stress debriefing (CISD) has been the focus of considerable attention as an initial intervention $(37,38)$. Despite the popularity of CISD, recent consensus has called its effectiveness into question and has emphasized the benefits of psychological first aid (PFA) as a more effective and relevant approach (39). Cognitive behavioral therapy (CBT) administered by mental health professionals remains the treatment of choice once individuals' basic and immediate needs have been met.

The assumption underlying CISD is that all individuals exposed to a traumatic event are at risk for stress reactions (including PTSD) and, as such, most everyone who has been exposed can benefit from the opportunity to learn about trauma manifestations and coping, and by sharing their experience. Arguments in favor of the CISD approach include the fact that it is a way to maintain morale, increase cohesions, and help workers feel empowered. Typically, all individuals exposed to a potentially traumatizing incident are invited to participate in a 3-4-h session within a few days of the event. Participants receive education about stress and ways of coping with it, messages about the normal nature of many such reactions, and are allowed to recount the event and are given the opportunity for further interventions.

Although it is well received as a frequent, if not standard, practice for emergency service personnel, there is no evidence that critical incident stress debriefing is effective in either reducing PTSD or in forestalling its later development $(30,37,40)$. Uncontrolled studies attesting to its efficacy typically focus on its alleged benefit of reducing or preventing PTSD reactions $(41,42)$. These factors have led to the standard application of CISD, 
despite accumulating evidence for its lack of efficacy $(43,44)$.

CISD is not intended for "direct" trauma victims, but for those who are "indirectly exposed" to the critical incident as a result of their professional responsibilities. As such, CISD is routinely administered to emergency services personnel and other professionals whose work entails regular exposure to traumatic events (e.g., law enforcement personnel, disaster workers such as the American Red Cross, firefighters, Emergency Medical Services, and military personnel). In practice, this distinction between "direct" and "indirect" exposure seems to be rather inconsistent and not enforced.

In addition to its questionable efficacy, criticisms of CISD include the inappropriateness of mandatory participation in debriefing activities, the potential for iatrogenic harm if traumatogenic material is introduced to group members who would not otherwise be exposed to such material, the possibility of psychological impact to highly suggestible persons when provided with psychoeducation about symptoms of distress, the fact that there is no opportunity to exclude at-risk individuals such as the intensely bereaved, those experiencing dissociation or psychosis and those physically ill, and the risks involved when there are no further opportunities for ongoing therapy or relevant interventions to those in need.

PFA is an evidence-informed approach for assisting individuals (children, adolescents, adults, and families) in the immediate aftermath of disaster and terrorism. It is designed to reduce the initial distress caused by traumatic events, and to foster short- and long-term adaptive functioning. PFA should be delivered by health professionals trained in its application. These are most commonly mental health specialists providing assistance to affected individuals as part of an organized disaster response effort, including first responder teams, incident command systems, primary and emergency health care providers, school crisis response teams, faith-based organizations, Community Emergency Response Teams, Medical Reserve Corps, the Citizens Corps, and disaster relief organizations. It can be implemented in diverse settings such as shelters, schools, hospitals, homes, staging areas, feeding locations, family assistance centers, and other community settings.

Providers establish a human connection in a nonintrusive, empathic manner, secure immediate and ongoing safety, and provide physical and emotional comfort. They also help survivors to define and articulate immediate needs. It is essential to offer concrete assistance and information to help address individuals' immediate needs and concerns and connect them as soon as possible to social support networks, including family members, friends, neighbors, and community helping resources. As a point of first contact for individuals who would benefit from PFA, emergency physicians are in a unique position to provide such support and reassurance and assist with concrete needs such as shelter. They also should be familiar with and provide referral to available mental health resources for those who are at risk for or are already displaying clinically significant mental health symptoms.

The literature on empirically validated interventions specifically directed to post-terrorism is limited, but there is substantial evidence for the effective treatment of the mental health disorders commonly seen after terrorism (45). Treatment of post-terrorism mental health disorders includes counseling or psychotherapy utilizing a cognitive behavioral approach as well as pharmacologic interventions. Emergency physicians participate in the therapeutic process by identifying those at risk, being aware of these interventions, and providing prompt referral for treatment.

Psychotherapeutic treatment of panic disorder is targeted at addressing fearfulness of bodily sensations. The treatment is intended to produce change by altering cognitive and associated processes. Through specialized interventions such as breathing retraining, relaxation techniques, and situational exposure, individuals learn to understand the reactions to their physical sensations that lead to their perception of panic as well as its impact on their functioning (5). Patients are helped to increase their emotional tolerance to the physical sensations associated with panic. Pharmacologic agents typically used to treat panic include selective serotonin reuptake inhibitors (e.g., fluoxetine) and tricyclic antidepressants (e.g., nortriptyline) (46). Researchers have demonstrated the successful ED initiation of treatment for panic disorder (under psychiatric consultation) with paroxetine $20 \mathrm{mg} /$ day for 1 month (6). Early interventions in the ED setting have been associated with "reduced long-term consequences" (47).

The initial treatment of mild anxiety also includes psychotherapeutic approaches such as cognitive behavioral therapy (CBT). Pharmacologic therapy, for patients whose anxiety disorder interferes with daily functioning, consists primarily of short-term treatment with anxiolytics such as benzodiazepines (48).

The best available evidence suggests that cognitive behavioral therapy is effective in reducing PTSD onset and progression (30). Psycho-education, anxiety management, cognitive restructuring, exposure and relapse prevention skills are appropriate CBT interventions. Ideally, CBT should be provided over successive weeks and should include considerable patient involvement to ensure that anxiety management, exposure, and cognitive restructuring is practiced daily. Pharmacologic treatment options for PTSD include selective serotonin reuptake 
inhibitors (e.g., fluoxetine) and anti-adrenergic agents such as clonidine (49).

Treatment of depression may involve counseling and psychotherapy or may require pharmacotherapy with antidepressant medication. Potential suicidal ideation requires emergent psychiatric evaluation. Common pharmacological anti-depressant medication classes include selective serotonin reuptake inhibitors (e.g., fluoxetine) and tricyclic antidepressants (e.g., nortriptyline).

\section{CONCLUSIONS}

Emergency medicine practitioners may well be the first contact for patients with mental health problems after terrorist incidents. In addition to preparing for the potential physical conditions and injuries associated with terrorism, they should be aware of and consider responses to the inevitable psychological injuries that will follow such incidents.

Although most people in the general population can be expected to recover spontaneously within several months after a terrorist event, other individuals are at increased risk of developing more debilitating mental health conditions that have been associated with postterrorist and disaster environments. Screening tools are available to help emergency practitioners identify them and refer them for more formal psychiatric evaluation and potential interventions to facilitate and speed healing. Emergency and other health practitioners can contribute to the recovery process by providing support, validation of feelings, and education on available resources.

\section{REFERENCES}

1. Alexander D. Psychological aspects of terrorism. Paper presented at 14th World Congress on Disaster and Emergency Medicine, 18 May 2005; Edinburgh, Scotland.

2. Norris FH, Friedman MJ, Watson PJ. 60,000 disaster victims speak: part II. Summary and implications of the disaster mental health research. Psychiatry 2002;65:240-60.

3. DiMaggio C, Galea S. The mental health and behavioral consequences of terrorism. In: Davis R, Lurigio A, Herman S, eds. Victims of crime, 3rd edn. London: Sage; 2006:147-61.

4. American Psychiatric Association, Task Force on DSM-IV. Diagnostic and statistical manual of mental disorders, $4^{\text {th }}$ edn (DSMIV). Washington, DC: American Psychiatric Association; 1994.

5. Barlow DH, Vermilyea J, Blanchard EB, Vermilyea BB, Di Nardo PA, Cerny JA. The phenomenon of panic. J Abnorm Psychol 1985;94:320-8

6. Wulsin L, Liu T, Storrow A, Evans S, Dewan N, Hamilton C. A randomized control trial of panic order treatment initiation in an emergency department chest pain center. Ann Emerg Med 2002; 39:139-43.

7. Bryant RA, Harvey AG, Guthrie RM, Moulds ML. A prospective study of psychophysiological arousal, acute stress disorder, and posttraumatic stress disorder. J Abnorm Psychol 2000;109:341-4.
8. American Psychiatric Association. Desk reference to the diagnostic criteria from DSM-III. Washington, DC: American Psychiatric Association; 1982.

9. American Psychiatric Association. Diagnostic and statistical manual of mental disorders (DSM-III-R), 3rd edn. Washington, DC: American Psychiatric Association; 1987.

10. Lovejoy DW, Diefenbach GJ, Licht DJ, Tolin DF. Tracking levels of psychiatric distress associated with the terrorist events of September 11, 2001: a review of the literature. J Insur Med 2003;35: $114-24$.

11. Galea S, Nandi A, Vlahov D. The epidemiology of post-traumatic stress disorder after disasters. Epidemiol Rev 2005;27:78-91.

12. Bremer J, Southwick S, Brett E, Fontana A. Dissociation and posttraumatic stress disorder in Vietnam combat veterans. Am J Psychiatry 1992;149:328-32.

13. Marmar CR, Weiss DS, Schlenger WE, et al. Peritraumatic dissociation and posttraumatic stress in male Vietnam theater veterans. Am J Psychiatry 1994;151:902-7.

14. Shalev AY, Freedman S. PTSD following terrorist attacks: a prospective evaluation. Am J Psychiatry 2005;162:1188-91.

15. Davidson JR, Foa EB. Refining criteria for posttraumatic stress disorder. Hosp Community Psychiatry 1991;42:259-61.

16. Norris FH, Friedman MJ, Watson PJ, Byrne CM, Diaz E, Kaniasty K. 60,000 disaster victims speak: part I. An empirical review of the empirical literature, 1981-2001. Psychiatry 2002;65:207-39.

17. DiMaggio C, Galea $\mathrm{S}$. The behavioral consequences of terrorism: a meta-analysis. Acad Emerg Med 2006;13:559-66.

18. Chen H, Chung H, Chen T, Fang L, Chen JP. The emotional distress in a community after the terrorist attack on the World Trade Center. Community Ment Health J 2003;39:157-65.

19. North CS. Psychiatric effects of disasters and terrorism. empirical basis from study of the Oklahoma City bombing. Paper presented at: American Psychopathological Association; Fear and anxiety: the benefits of translational research, New York: March 2002.

20. Galea S, Resnick H, Ahern J, et al. Posttraumatic stress disorder in Manhattan, New York City, after the September 11th terrorist attacks. J Urban Health 2002;79:340-53.

21. Factor $\mathrm{SH}, \mathrm{Wu} \mathrm{Y}$, Monserrate J, et al. Drug use frequency among street-recruited heroin and cocaine users in Harlem and the Bronx before and after September 11, 2001. J Urban Health 2002;79: 404-8.

22. Foy DW, Sipprelle RC, Rueger DB, Carroll EM. Etiology of posttraumatic stress disorder in Vietnam veterans: analysis of premilitary, military, and combat exposure influences. J Consult Clin Psychol 1984;52:79-87.

23. Martin L, Rosen LN, Durand DB, Knudson KH, Stretch RH. Psychological and physical health effects of sexual assaults and nonsexual traumas among male and female United States Army soldiers. Behav Med 2000;26:23-33.

24. Smith J, Prior M. Temperament and stress resilience in school-age children: a within-families study. J Am Acad Child Adolesc Psychiatry $1995 ; 34: 168-79$.

25. Garmezy N, Masten AS, Tellegen A. The study of stress and competence in children: a building block for developmental psychopathology. Child Dev 1984;55:97-111.

26. Masten AS, Hubbard JJ, Gest SD, Tellegen A, Garmezy N, Ramirez M. Competence in the context of adversity: pathways to resilience and maladaptation from childhood to late adolescence. Dev Psychopathol 1999;11:143-69.

27. Luthar SS, Cicchetti D, Becker B. The construct of resilience: a critical evaluation and guidelines for future work. Child Dev 2000;71:543-62.

28. Grizenko N, Pawliuk N. Risk and protective factors for disruptive behavior disorders in children. Am J Orthopsychiatry 1994;64: 534-44.

29. Masten AS. Ordinary magic. Resilience processes in development. Am Psychol 2001;56:227-38.

30. Clauw DJ, Engel CC Jr, Aronowitz R, et al. Unexplained symptoms after terrorism and war: an expert consensus statement. J Occup Environ Med 2003;45:1040-8. 
31. Pandya A, Weiden PJ. Trauma and disaster in psychiatrically vulnerable populations. J Psychiatr Pract 2001;7:426-30.

32. Schlenger WE, Jernigan NE. Mental health issues in disasters and terrorist attacks. Ethn Dis 2003;13(3 Suppl 3):S3-89-93.

33. Riggs DS, Byrne CA, Weathers FW, Litz BT. The quality of the intimate relationships of male Vietnam veterans: problems associated with posttraumatic stress disorder. J Trauma Stress 1998;11: 87-101.

34. McFarlane A, de Girolamo G. [Post-traumatic stress disorder: will the future be different from the past? (Italian)] Epidemiol Psichiatr Soc $1998 ; 7: 1-9$.

35. Tarrier N, Sommerfield C, Pilgrim H. Relatives' expressed emotion (EE) and PTSD treatment outcome. Psychol Med 1999;29: 801-11.

36. Ruzek J. Coping with PTSD and recommended lifestyle changes for PTSD patients. Available at: http://www.ncptsd.va.gov/ncmain/ ncdocs/fact_shts/fs_coping.html. Accessed February 27, 2006.

37. Peterson AL, Nicolas MG, McGraw K, Englert D, Blackman LR. Psychological intervention with mortuary workers after the September 11 attack: the Dover Behavioral Health Consultant model. Mil Med 2002;167(9 Suppl):83-6.

38. Everly GS, Mitchell JT. The debriefing "controversy" and crisis intervention: a review of the lexical and substantive issues. Int J Emerg Ment Health 2000;2:211-25.

39. Psychological first aid: field operations guide. Available at: www.ncptsd.va.gov/pfa/PFA_9_6_05_Final.pdf. Accessed October 16, 2006.

40. Boris NW, Ou AC, Singh R. Preventing post-traumatic stress disorder after mass exposure to violence. Biosecur Bioterror 2005; 3:154-63; discussion 164-5.

41. Deahl M, Srinivasan M, Jones N, Thomas J, Neblett C, Jolly A. Preventing psychological trauma in soldiers: the role of operational stress training and psychological debriefing. Br J Med Psychol 2000;73:77-85.

42. Mitchell JT, Everly GS. The critical incident stress debriefing (CISD) and the prevention of work related traumatic stress among high-risk occupational groups. In: Everly GS, Lating J, eds. Psychotraumatology: key papers and core concepts in post-traumatic stress. New York: Plenum Press; 1995:159-69.

43. Litz B, Gray M, Bryant R, Adler A. Early intervention for trauma: current status and future directions. Clin Psychol Sci Pract 2002; 9:112-34.

44. Van Emmerik A, Kamphuis J, Hulsbosch A, Emmelkamp P. Singlesession debriefing after psychological trauma: a meta-analysis. Lancet 2002;360:766-70.

45. Yehuda R, Hyman SE. The impact of terrorism on brain, and behavior: what we know and what we need to know. Neuropsychopharmacology 2005;30:1773-80.
46. Dickey M, Hendrix M. Anxiety disorders. Available at: http:// www.nimh.nih.gov/publicat/anxiety.cfm\#anx9. Accessed March 16, 2006.

47. Zun L. Panic disorder: diagnosis and treatment in emergency medicine. Acad Emerg Med 1997;30:92-6.

48. Gliatto MF. Generalized anxiety disorder. Am Fam Physician 2000;62:1591-600, 1602

49. Lange JT, Lange CL, Cabaltica RB. Primary care treatment of post-traumatic stress disorder. Am Fam Physician 2000;62:103540, 1046.

50. American Psychiataric Association. Handbook of psychiatric measures, $2^{\text {nd }}$ edn. Washington, DC: American Psychiatric Association; 2005.

51. Rumpf HJ, Meyer C, Hapke U, John U. Screening for mental health: validity of the MHI-5 using DSM-IV Axis I psychiatric disorders as gold standard. Psychiatry Res 2001;105:243-53.

52. Schmitz N, Kruse J, Heckrath C, Alberti L, Tress W. Diagnosing mental disorders in primary care: the General Health Questionnaire (GHQ) and the Symptom Check List (SCL-90-R) as screening instruments. Soc Psychiatry Psychiatr Epidemiol 1999;34:360-6.

53. Derogatis LR, Melisaratos N. The Brief Symptom Inventory: an introductory report. Psychol Med 1983;13:595-605.

54. Sarason IG, Johnson JH, Siegel JM. Assessing the impact of life changes: development of the Life Experiences Survey. J Consult Clin Psychol 1978;46:932-46.

55. US Department of Veterans Affairs. Screening for PTSD in a Primary Care Setting: a National Center for PTSD fact sheet. Available at: http://www.ncptsd.va.gov/ncmain/ncdocs/fact_shts/ fs_screen_disaster.html. Accessed January 18, 2006.

56. Lang AJ, Laffaye C, Satz LE, Dresselhaus TR, Stein MB. Sensitivity and specificity of the PTSD checklist in detecting PTSD in female veterans in primary care. J Trauma Stress 2003;16:257-64.

57. Lang AJ, Stein MB. An abbreviated PTSD checklist for use as a screening instrument in primary care. Behav Res Ther 2005;43: 585-94.

58. Weathers FW, Huska JA, Keane TM. PCL-C for DSM-IV. Boston, MA. National Center for PTSD - Behavioral Science Division; 1991.

59. Kroenke K, Spitzer RL, Williams JB. The PHQ-9: validity of a brief depression severity measure. J Gen Intern Med 2001;16: 606-13.

60. Babor TF, Dolinsky ZS, Meyer RE, Hesselbrock M, Hofmann M, Tennen H. Types of alcoholics: concurrent and predictive validity of some common classification schemes. Br J Addict 1992;87: 1415-31.

61. Babor TF, Hofmann M, DelBoca FK, et al. Types of alcoholics, I. Evidence for an empirically derived typology based on indicators of vulnerability and severity. Arch Gen Psychiatry 1992;49:599-608. 